\title{
Evaluation Criteria and Benefit Analysis of Mixing Process in Anaerobic Digesters of Biogas Plants
}

\author{
Fosca $\mathrm{CONTI}^{1 *}$, Abdessamad SAIDI ${ }^{2}$, Markus GOLDBRUNNER $^{3}$ \\ ${ }^{1}$ Department of Chemical Sciences, University of Padova, Padova, Italy \\ ${ }^{2,3}$ Institute of new Energy Systems, Technische Hochschule Ingolstadt, Ingolstadt, Germany
}

\begin{abstract}
A valid method to evaluate decisions of a project proposal is the so-called cost-benefit analysis. Criteria are selected and properly weighted to determine if the project is effective and feasible. The present research study is focused on methodical selection of design parameters to install two propeller mixers inside anaerobic digesters of biogas plants. A cylindrical tank of $1400 \mathrm{~m}^{3}$ was considered. For the model-based optimisation, the substrate was considered as a non-Newtonian fluid with a density of $1090 \mathrm{~kg} / \mathrm{m}^{3}$. The Oswald-de Waele power-law model was selected to account for the rheological behaviour of the fluid. Installation parameters of the mixers were rotational angles and heights of the shafts of the two propellers. A computational model was developed to simulate the fluid dynamics depending on the mixing process inside the tank. Several configurations were analysed according to evaluating criteria such as the value of the fluid velocity, its distribution along the three spatial dimensions, and the power consumption to rotate the mixers. The maximum fluid velocity and minimum power consumption were observed when the propellers are located at intermediate height inside the tank and with the shafts perpendicular to the tank radius. With this configuration, the fluid reaches a maximum velocity of $0.28 \mathrm{~m} / \mathrm{s}$. According to the investigation, it is evident that mixing systems with propeller shafts deep-seated and parallel to the tank radius should be avoided, both in term of efficiency of the fluid mixing distribution and in term of power consumption.
\end{abstract}

Keywords - Anaerobic digester; biomass; computational fluid dynamics (CFD); CostBenefit Analysis (CBA); evaluation criteria; flow velocity; full scale biogas digester; mixing; propeller

\begin{tabular}{|lll|}
\hline Nomenclature & & degree \\
$\alpha$ & Angle of the mixer rotation in the (x-y) plane, anticlockwise & $\mathrm{m}$ \\
$h$ & Height of the mixer location in the digester & $\mathrm{m} / \mathrm{s}$ \\
$v_{G}, v_{G, X}, v_{G, Y}, v_{G, Z}$ & Global flow velocity and its axial components in the digester & $\mathrm{W}$ \\
$P$ & Power consumption & $\mathrm{N} \cdot \mathrm{m}$ \\
$M$ & Torque moment & $\mathrm{m} / \mathrm{s}$ \\
$U$ & Distribution of the flow velocity in 16 subregions & - \\
$\varepsilon v_{X}, v_{Y}, v_{Z}$ & Distribution of the axial components of the flow velocity & \\
$\chi v_{i}$ & Fraction of velocity component along i-axis & - \\
$W$ & Weight of each criterion & \\
\hline
\end{tabular}

* Corresponding author.

E-mail address: fosca.conti@unipd.it 


\begin{tabular}{|lll|}
\hline$\varphi$ & Degree of fulfilment & - \\
$\sigma$ & 2-criteria technical benefit parameter & $1 / \mathrm{N}$ \\
$\tau$ & 5-criteria technical benefit parameter & $\%$ \\
$R e$ & Reynolds number & - \\
\hline
\end{tabular}

\section{INTRODUCTION}

In a global concept of circular economy, environmental choices are necessary so that every project considers the way ideas, materials and components are produced, used, recovered and regenerated. To evaluate the decisions of a project proposal, there are several valid methods, such as the Net Present Value, the Internal Rate of Return and the Cost-Benefit Analysis (CBA). In the present study, the CBA process is employed to make proper decisions on the design of mixing systems in anaerobic digesters of biogas plants [1]. Generally, the purpose of the CBA in project management is to have a systematic approach to figure out the advantages and disadvantages of various pathways of the project. It includes transactions, tasks, business requirements and investment. Main purposes in using CBA are:

- Determine if the project is effective and feasible;

- Offer a baseline for comparing projects;

- Indicate alternatives, if the benefits are not dominant;

- Map the costs and benefits over a relevant period of time.

Each purpose is related to a sensitivity analysis, i.e. each step of a CBA is affected by a study of how the uncertainty in the output can be apportioned to different sources of uncertainty in its input. There are many factors that impact the accuracy of such analysing approaches. Inaccuracies can be mainly caused by the following operating parameters:

- Improper use of heuristics;

- Attesting unsuitable importance to subjective impressions;

- Relying inappropriate ranking on data collected from similar projects;

- Confirmation bias or only using data, which fits with the wished results.

CBA processes are based on criteria, to evaluate whether the project will have positive or negative consequences. The evaluation criteria are based on the effects on user and nonusers, including the environment and social impacts. In the present study, 441 configurations of the mixing system in a cylindrical digester are analysed. The digester provides the ideal microbiological conditions for efficient conversion of organic materials into biogas [2]-[4]. Therefore, the design needs to minimize inefficient short-circuiting of feedstock, ensures a high gas yield and reliable operations [5]. Selected evaluation criteria for the efficiency of the mixing process are related to the intensity of the fluid velocity [6], to its homogenic distribution inside the digester, and to the power consumption, which is required to operate the stirrers [7]. CFD methods were applied to the anaerobic digester [8], [9].

\section{METHOD AND EXPERIMENTS}

\subsection{Tank Design}

The tank is considered as a cylinder with a volume of $1400 \mathrm{~m}^{3}$. In Fig. 1 the geometrical parameters are indicated. Digesters in biogas plants are covered by a double membrane to hold 
the gas. In the present tank, a cylindrical volume of ca. $16 \mathrm{~m}^{3}$ is located in the middle of the tank to take in consideration the support, which sustains roof and membrane. However, the reduction of active volume is assumed to be negligible [10]. Two horizontal propellers are implemented to perform the mixing process. The propellers can be positioned at 3 different heights $(h$, in Fig. 1(a)) and have 7 different rotation angles ( $\alpha$, in Fig. 1(b)). Therefore, a total number of 441 different configurations are possible [11]. In the present study, the 441 configurations are investigated to establish the design, which delivers the optimum operation results.

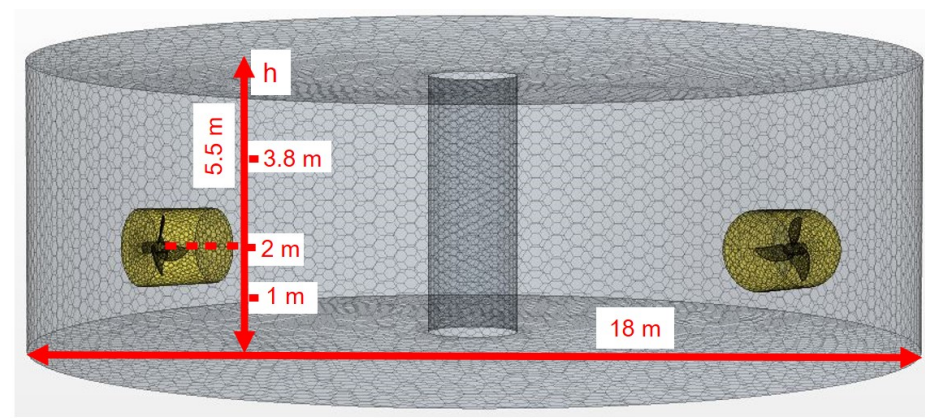

(a)

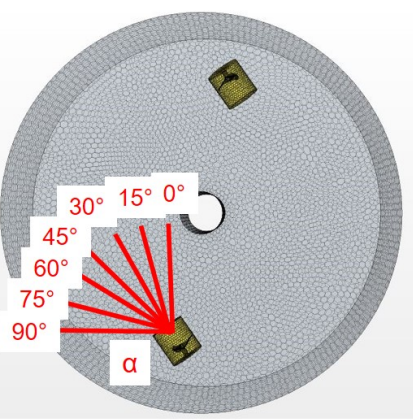

(b)

Fig. 1. 3D-CAD geometry of tank and propellers with meshing: (a) Side view with localization of stirrers at different heights $h$, and (b) top view with rotation of stirrers at different angles $\alpha$.

\subsection{Modelling Procedure and CFD Setting}

Digester substrates are classified as non-Newtonian fluids because of the shear-dependent behaviour of the viscosity [12]-[14]. In the present study, the Oswald-de Waele power-law model was selected for the simulation of a fluid with a density of $1090 \mathrm{~kg} / \mathrm{m}^{3}$ [15].

To mesh surfaces and volumes inherent to the tank design, the polyhedral mesher was used [16]. A grid of ca. $3 \cdot 10^{6}$ cells was selected [17]. To dedicate a sufficient accuracy in the regions around the propellers, the wall of the tank, the central support as well as the bottom and the top surfaces of the tank, the cells had different dimensions in relation to the domains. Fig. 1 shows the cylindrical rotating subregions created around each propeller and the $3 D-C A D$ geometry imported into the CFD platform. For the simulations, the commercial software Star-CCM+, from CD-Adapco Siemens, was used. The moving reference frame approach was applied [18]. According to the assumptions of $\mathrm{Wu}$ [19] for turbulence models and time-dependent fluctuating parameters, the Reynolds-averaged Navier-Stokes equations were selected along with the k- $\varepsilon$ turbulence model [20]. To contemplate the wall boundary effects, the standard k- $\omega$ model was applied [21], [22]. On the wall and bottom surface layers of the tank no-slip conditions were adopted, whereas the fluid surface on the top (transition to gas) was modelled with slip conditions [23]. Details of the modelling procedure and CFD setting are presents in [10], [11], [17]. 


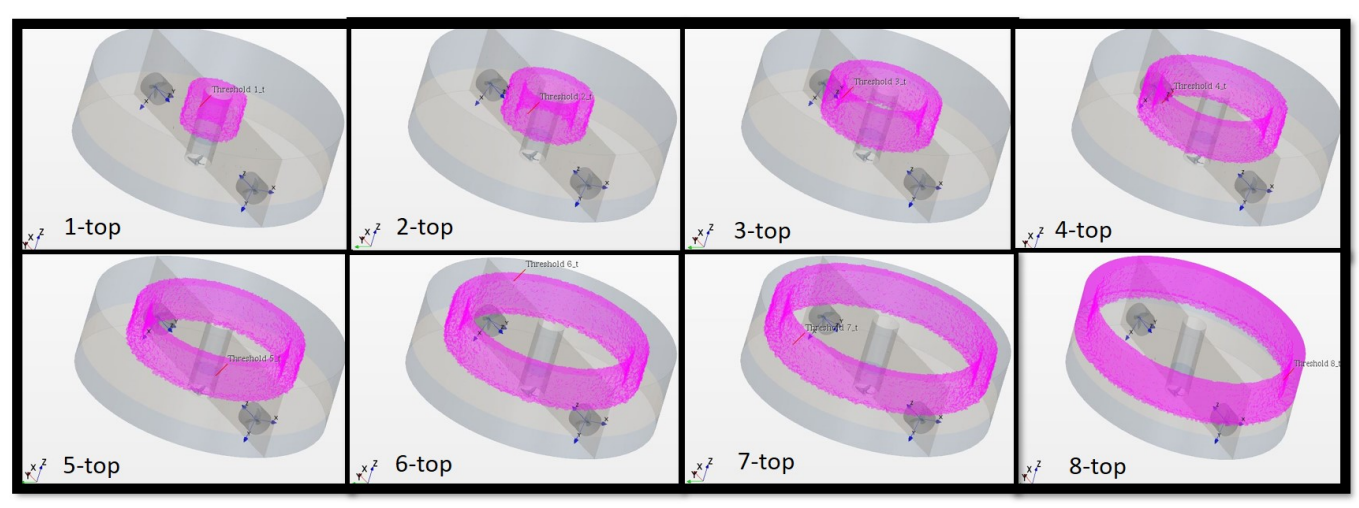

Fig. 2. Examples of partition of the tank volume (grey) in circular subregions (purple): a) 1_b; b) 3_b; c) 5_b; d) 7 _b top subregions [11].

Both to identify local effects and distributions and to easily illustrate the results of the CFD simulations with higher accuracy, the tank volume was divided by an imaginary horizontal plane in two cylinders, which are labelled as top, $t$, and bottom, $b$. In each cylinder, eight circular subregions were designed around the central support [11]. Fig. 2 shows eight subregions in the top $t$-cylinder.

\subsection{Power Consumption}

To validate the CFD model, the simulated required power consumption of the agitators was compared to experimental results on a laboratory scaled facility [24], [25]. In Fig. 3(a) a photo of the equipment developed in the laboratory is reported. Moreover, the mixing process was monitored in-situ at the reference biogas plant of the project partner UTS [26]. Fig. 3(b) shows the scheme of the measuring setup used at the anaerobic digester. The power consumption $P$ of the mixing system was calculated using the torque moment $M$ of each propeller at the corresponding rotational speed $\omega$ [27]-[29], as indicated by Eq. (1).

$$
P=P_{1}+P_{2}=\frac{2 \pi}{60} \cdot \sum_{i=1}^{441}\left(\omega_{1 i} \cdot M_{1 i}+\omega_{2 i} \cdot M_{2 i}\right)
$$

In-situ, the torque moment was measured at the shaft of the propeller using a Rhewa type 82e-plus sensor. Data were collected continuously each $20 \mathrm{sec}$ for 53 days. 


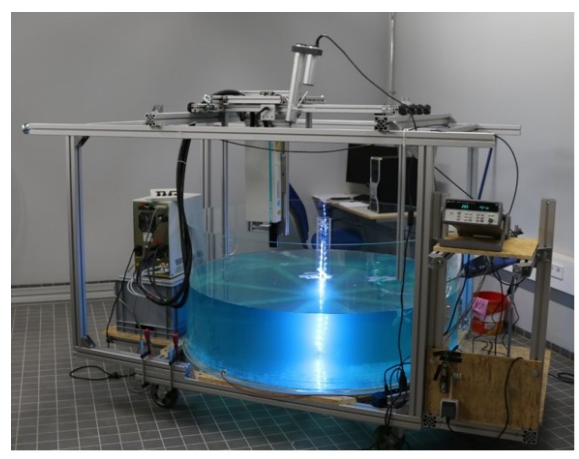

(a)

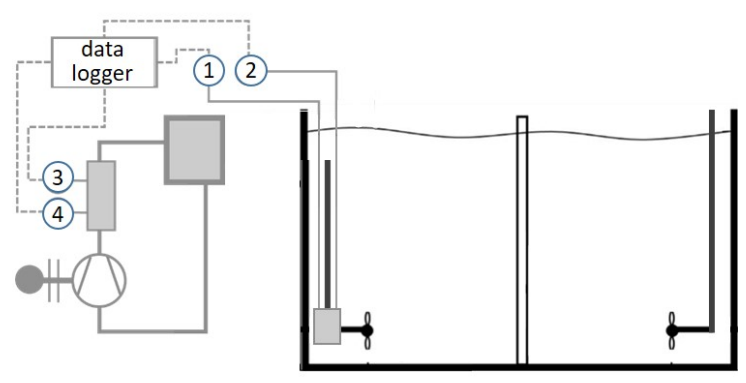

(b)

Fig. 3. Mixing system with two horizontal propellers. a) Photo of the laboratory scaled facility, where the tank has a diameter of $1.5 \mathrm{~m}$; b) Scheme of the hydraulic cycle with electrical power supply: Numbers indicate sensors for (1) torque, (2) thrust, (3) pressure, and (4) flowrate.

\subsection{Evaluating Criteria}

According to the present study, quality of the mixing is mainly expressed by the homogeneity of the fluid velocity and absence of dead zones [30]. For the total number of 441 configurations, the velocity vector was analysed in module, axial components and distribution in the grid of $3 \cdot 10^{6}$ cells and in the 16 circular subregions around the central support. Five criteria were introduced to evaluate the configurations as a reliable decision base for the design of the mixing system in terms of the propeller position (angle and height). The significance of all 5 criteria was quantified by a weight index $W$ between 4 and 2 . In Table 1 all five evaluation criteria and the corresponding weight indexes are listed. The highest weight was attributed to the fluid velocity criterion, in particular to the averaged value of the global flow velocity $v_{G}$ :

$$
v_{G}=\frac{\sum_{i}^{n}\left|v_{i}\right|}{n}
$$

In Eq. (2) $n$ indicates the number of cells used in the CFD simulation model, which is $3 \cdot 10^{6}$ in the present case. To evaluate the distribution of the axial components of the velocity vector, the parameter $\varepsilon$ was introduced, like in Eq. (3). Since an optimized mixing process is characterized by a continuous uniform distribution of the velocity directions [31], [32], the share of each vector coordinate has to be as equal as possible and therefore amount $33 \%$. As long as the deviation from this ideal condition grows, the parameter $\varepsilon$ increases so that the configuration with the minimum value of $\varepsilon$ represents the proper decision according to this criterion. In Eq. (3), $\chi$ indicates the fraction of velocity component:

$$
\varepsilon_{v x, v y, v z}=\sqrt{\sum_{i=1}^{441}\left(x_{v_{x i}}-\frac{1}{3}\right)^{2}+\left(x_{v_{y i}}-\frac{1}{3}\right)^{2}+\left(x_{v_{z i}}-\frac{1}{3}\right)^{2}}
$$


TABle 1. CRITERIA AND EVALUATION WeIGHTS USED FOR BENEFIT ANALYSIS

\begin{tabular}{|c|c|c|c|c|}
\hline Symbol & $\begin{array}{l}\text { Evaluation } \\
\text { method }\end{array}$ & Name of criterion parameter & Description of criterion parameter & $\begin{array}{l}\text { Weight of } \\
\text { criterion, } W\end{array}$ \\
\hline$P$ & Eq. (1) & Power consumption & $\begin{array}{l}\text { Parameter to determine the required } \\
\text { power to rotate the two propellers } \\
\text { mixing system }\end{array}$ & 4 \\
\hline$v_{G}$ & Eq. (2) & Global flow velocity & $\begin{array}{l}\text { Indication of flow velocity intensity } \\
\text { inside the digester }\end{array}$ & 4 \\
\hline $\begin{array}{l}\varepsilon v_{X}, v_{Y} \\
v_{Z}\end{array}$ & Eq. (3) & $\begin{array}{l}\text { distribution of the velocity axial } \\
\text { components }\end{array}$ & $\begin{array}{l}\text { Indication of non-homogeneous } \\
\text { mixing along the three directions }\end{array}$ & 3 \\
\hline$U$ & Eq. (4) & velocity distribution in subregions & $\begin{array}{l}\text { non-uniformity distribution of the fluid } \\
\text { velocity in the } 16 \text { subregions } \\
\text { ( } 8 \text { bottom and } 8 \text { top ring subregions) }\end{array}$ & 2 \\
\hline$\chi_{v_{z+}}$ & Eq. (5) & $\begin{array}{l}\text { fraction of positive z-component of } \\
\text { velocity }\end{array}$ & $\begin{array}{l}\text { Determination of up (positive)/down } \\
\text { (negative) vertical component of the } \\
\text { velocity vector }\end{array}$ & 2 \\
\hline
\end{tabular}

Due to its relevance in terms of energy cost, also the power consumption criterion, indicated in Eq. (1), was characterized by the maximum value of the weight index, i.e. 4.

Criterion $U$ describes the non-uniformity distribution of the fluid velocity in the eight bottom and top ring subregions and is defined according to Eq. (4):

$$
U=\sqrt{\sum_{i=1}^{16}\left(\left|v_{G}\right|-\left|v_{G, i}\right|\right)^{2}}
$$

The lower the value of $U$, the higher is the mixing quality. Therefore, the minimum value of $U$ corresponds to a degree of full fulfilment. The weight of this parameter was set to 2 .

Poorly mixed volume can cause solid parts floating at the surface or settling at the bottom, with the consequence to have dead regions, where the digestion process gets shut down. In Eq. (5) $x_{v_{z+}}$ is the fraction of the vertical component of the velocity vector, i.e. along the positive z-axis. The maximum performance is obtained at high values of $x_{v_{z+}}$ :

$$
x_{v_{z+}}=\frac{\sum v_{z+i}}{\sum v_{z-i}}
$$

Table 2 lists the limiting conditions for the degrees of fulfilment for the criteria, which range between 0 and 9 . 
TABLE 2. LIMITS OF DEGREE OF FULFILMENT RANGE $(\varphi)$ AND CORRESPONDING CONDITIONS FOR CRITERIA PARAMETERS

\begin{tabular}{cccccc}
\hline $\begin{array}{c}\text { Degree of } \\
\text { fulfilment }\end{array}$ & $\boldsymbol{P}$ & $\boldsymbol{v G}_{\boldsymbol{G}}$ & $\boldsymbol{\varepsilon}_{v x, v y, v z}$ & $\boldsymbol{U}$ & $x_{v_{z+}}$ \\
\hline $\boldsymbol{\varphi}=\mathbf{0}$ & Max & Min & $\max$ & $\max$ & $\min$ \\
$\boldsymbol{\varphi}=\mathbf{9}$ & Min & Max & $\min$ & $\min$ & $\max$ \\
\hline
\end{tabular}

By defining the technical benefit parameter $\tau$ as the product of each criterion's weight and its corresponding degree of fulfillment, the ideal design is represented by a configuration where all criteria are summed with the maximum performance, i.e. $\varphi$ is 9 for all parameters. In this case, an ideal total score of 135 is obtained using Eq. (6):

$$
(\tau) \text { ideal }=\sum_{i=1}^{5} W_{i} \cdot\left(\varphi_{i}\right)_{\max }
$$

\section{RESULTS AND DISCUSSION}

\subsection{Fluid Flow Velocity}

To describe the fluid motion inside the cylindrical tank, the impact of the position of the propellers on the flow velocity was analysed. In Fig. 4 the averaged value of the velocity is plotted over the rotation angle of the two propellers.

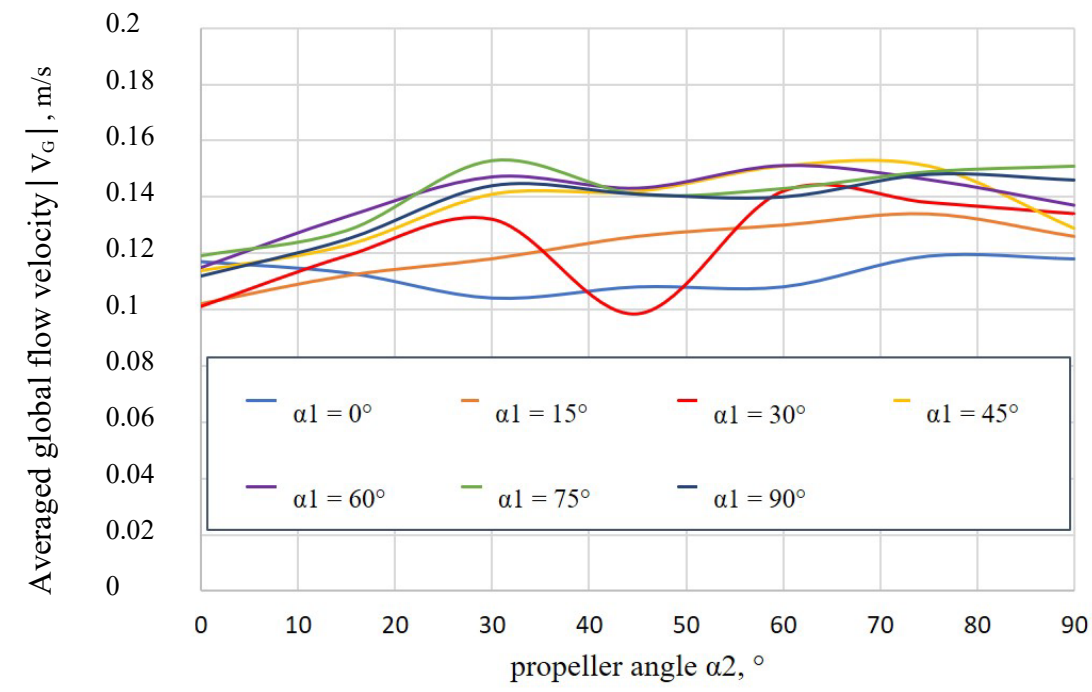

Fig. 4. Fluid velocity profile as function of the rotation angles of mixer $2(\alpha 2)$, for seven different rotation angles of mixer $1(\alpha 1)$.

As expected, low values are determined in cases, where the propeller is located with the shaft along the tank radius or slightly tilted from the parallel orientation. Indeed, for $\alpha=0^{\circ}$ 
(blue line), the profiles with minimum values are observed. If the angle is $15^{\circ}$ (orange line), a similar trend is observed. Other predictable results are the maximum velocity values for the perpendicular position of the shaft to the tank radius. The global velocity values range between 0.09 and $0.15 \mathrm{~m} / \mathrm{s}$.

In Fig. 5 the dependency of the fluid velocity on the propeller heights is illustrated. Besides the global velocity, $v_{G}$, the components along the three dimensions are presented. A uniformity in the maximum and minimum values is observed. The fluid in the circular subregions near the central support result to flow very slowly, both in the top and bottom subregions. This is evident in the yellow (subregions $1 \_b$ and $1 \_t$ ), red (subregions $2 \_b$ and $2 \_t$ ), and green (subregions $3 \_b$ and $3 \_t$ ) profiles in Fig. 5. On the contrary, high velocity values are observed in the external subregions ( 7 and 6). Exceptions are the top and bottom subregions in contact with the tank wall (8_t and 8 b, brown profiles). For the wall boundaries, stationary conditions are specified in the simulation model. The results of the CFD calculations validate the effects in terms of roughness, friction and adhesion of the fluid with the tank wall. With respect to the positioning of the propellers, the best fluid velocity was observed when the propeller is at intermediate height, ca. $2 \mathrm{~m}$ above the bottom of the tank. With this configuration, the fluid reaches a maximum velocity of $0.28 \mathrm{~m} / \mathrm{s}$. In consideration of the $\mathrm{x}-, \mathrm{y}-$, and $\mathrm{z}$-components, the latter shows apparently casual profiles, like in Fig. 5(d). The gravitational force along the z-direction increases the complexity of the fluid dynamic and must be considered in the global motion induced by the propellers.

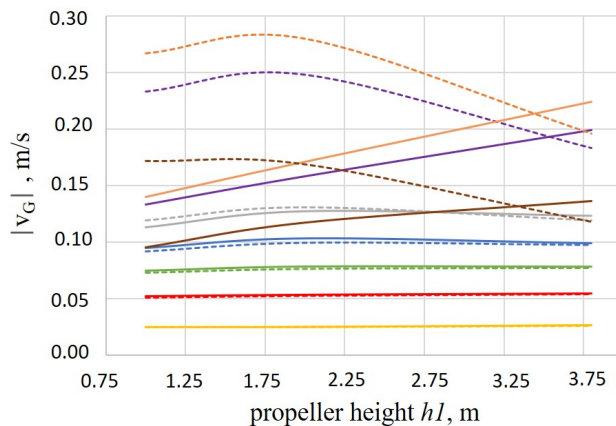

(a)

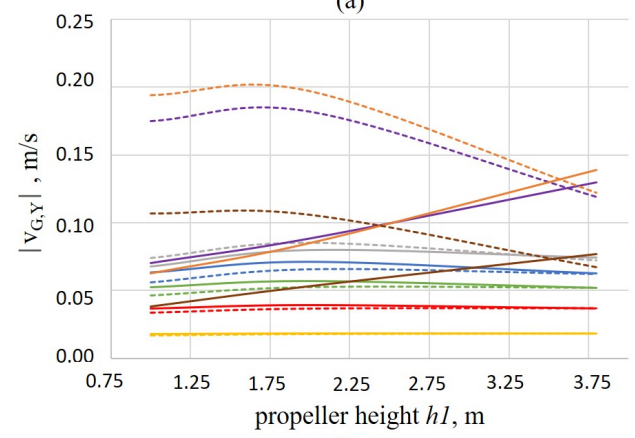

(c)

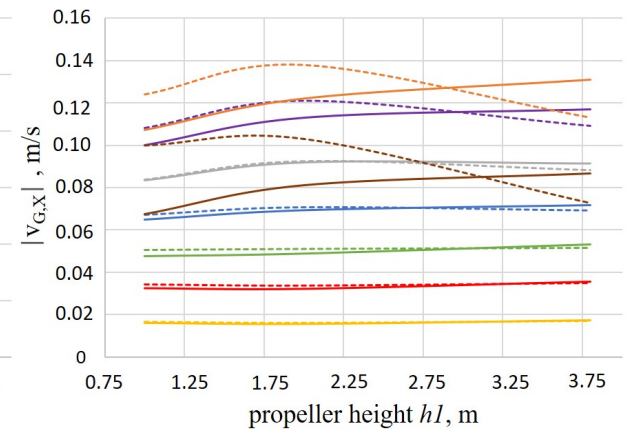

(b)

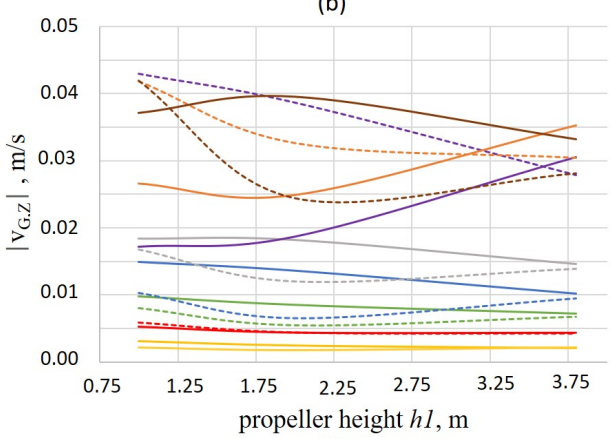

(d)

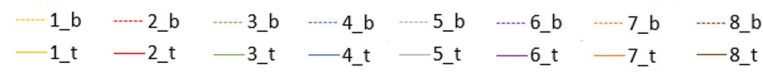

Fig. 5. Dependency of (a) global fluid velocity $v_{G}$ and axial components (b) x, (c) y, and (d) z with the height of propeller 1 (hl). Profiles refer to 8 bottom (\#_b, dotted lines) and 8 top (\#_t, continuous lines) circular subregions (see Fig. 2). 
Efficiency of digestion is strongly influenced by the flow velocity in each direction of the anaerobic digester. High velocity is recommended below an optimum level, which avoids the formation of pockets of different environments ultimately causing uncontrolled digestion. On the other side, above this level the mixing can be detrimental to the activity of the microbial consortia responsible of the gas production because of breakup of the flocculation structures of the microorganisms at high flow velocity [33], [34]. Quantification of the optimum level of flow velocity requires the analysis of the specific anaerobic digester, i.e. not only the type of mixing system but also the nature of the biomass. Therefore, the creation of turbulent or laminar flows is not a valid and general indication of optimum mixing. However, it is useful to describe the flows on the basis of the Reynolds number, $R e$, which quantifies the level of turbulence inside a liquid. In the present study the fluid is under stirring by propellers. Therefore, $R e$ is related not only to the density $\rho$ and dynamic viscosity $\eta$ of the fluid, but also to the rotation speed $N$ and diameter $d$ of the propeller with the expression of Eq. (7):

$$
R e=\frac{\rho N d^{2}}{\eta}
$$

According to the reference UTS biogas plant [26], a substrate with $\rho=1090 \mathrm{~kg} \mathrm{~m}^{-3}$ and $\eta=5 \mathrm{~Pa}$ s was mixed by two propellers with $d 1=0.94 \mathrm{~m}$ or $d 2=1.50 \mathrm{~m}$. By applying a rotational speed of $150 \mathrm{rpm}, R e$ results to be 3025 or 7705 respectively. The high values confirm the correct decision to use turbulence models.

\subsection{Evaluation of Mixing Configurations and Benefit Analysis using Two Criteria}

In the previous section, the mixing configurations were evaluated merely according the flow velocity $v_{G}$ as a criterion. The quality of the mixing was quantified by the amount of the velocity of the fluid. This approach shows the restriction to not consider the energy consumption required to rotate the stirrers. To overcome this limitation, parameter $\sigma$ was introduces in Eq. (8), which balances both criteria:

$$
\sigma=\frac{v_{G}}{P}
$$

In Fig. 6 the results of the evaluation of all 441 configurations are presented. Parameter $\sigma$ shows a general increasing trend. The maximum value was calculated at $\sigma_{M A X}=5.5 \cdot 10^{-6} \mathrm{~N}^{-1}$ and was obtained with configuration nr. 357, which corresponds to have the settings $\alpha 1=75^{\circ}$, $\alpha 2=60^{\circ}, h 1=2 \mathrm{~m}$ and $h 2=3.8 \mathrm{~m}$. According to the plots, the drop of $\sigma$ in several zones, which are highlighted in green, is remarkable. They correspond to configurations where one propeller is located at an angle $\alpha=0^{\circ}$. Results in orange zone refer to configurations where both propellers have $\alpha=0^{\circ}$. After this investigation it is evident that mixing systems with propeller shaft parallel to the tank radius should be avoided, either in terms of the efficiency of the fluid mixing and the power consumption. Because of the presence of the seven green zones, where $\sigma$ values drop, one is expected to observe zones, where $\sigma$ values rise. On the contrary, no uniform zones can be distinguished in the plot of Fig. 6. Considerations should be limited to the seven relative maxima, marked in dotted cycles. A general trend of the maxima is evident. They correspond to configurations, where both propellers are located at 
high positions of 2 or $3.8 \mathrm{~m}$. These results suggest that mixing systems with the propeller shafts near the bottom of the tank should be avoided.

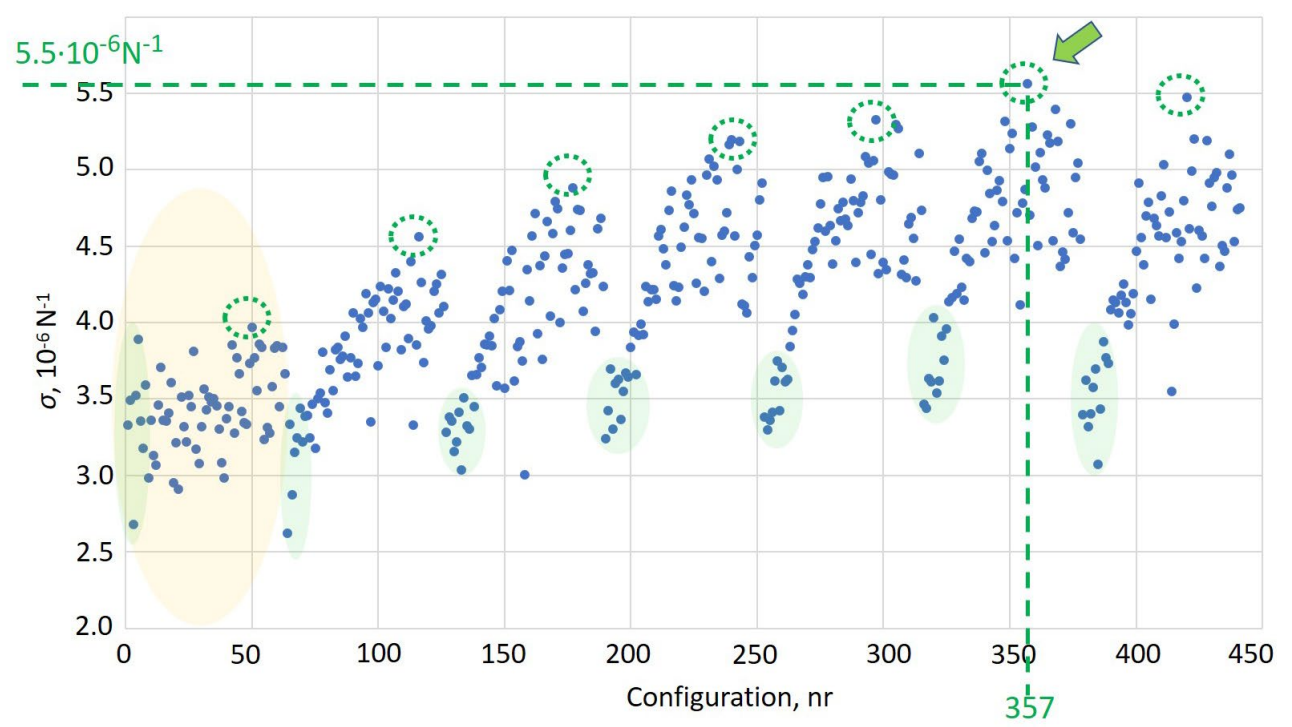

Fig. 6. Correlation between technical benefit and mixing configuration type using two criteria, fluid velocity and power consumption. Best scenario is indicated by the arrow and corresponds to configuration 357 with $\alpha 1=75^{\circ}, \alpha 2=60^{\circ}$, $h 1=2 \mathrm{~m}, h 2=3.8 \mathrm{~m}$.

\subsection{Evaluation of Mixing Configurations and Benefit Analysis using Five Criteria}

A refinement of the previous evaluation based on the parameter $\sigma$ is to consider all five criteria described in section 2.4 and the specific relative weight $W$. For this reason, the ideal technical benefit parameter $(\tau)$ ideal, which is defined according to Eq. (6), is generalized in Eq. (9) and expressed as a percentage value:

$$
\tau=\frac{\sum_{i=1}^{5} \varphi_{i} \cdot W_{i}}{135} \cdot 100
$$

Fig. 7 shows the results of the evaluation for all 441 configurations. Parameter $\tau$ ranges between 24 and $72 \%$ with an average value at $53 \%$. The configuration with the best benefit parameter $\tau_{M A X}=72 \%$ corresponds to the setting $\alpha 1=75^{\circ}, \alpha 2=75^{\circ}, h 1=3.8 \mathrm{~m}$ and $h 2=3.8 \mathrm{~m}$. This configuration is slightly different from that with $\sigma_{M A X}$, which results to have a technical benefit of $69 \%$. This observation further establishes that the design with high angles and high locations is convenient. Differently from the analysis based on $\sigma$, the use of five criteria spreads the results in wider distribution so that no precise characteristic zones can be distinguished, as it was for the green zones in Fig. 6. However, the main conclusions are confirmed, i.e. that configurations with propellers near the tank bottom and with rotational shaft parallel to tank radius are less efficient. 


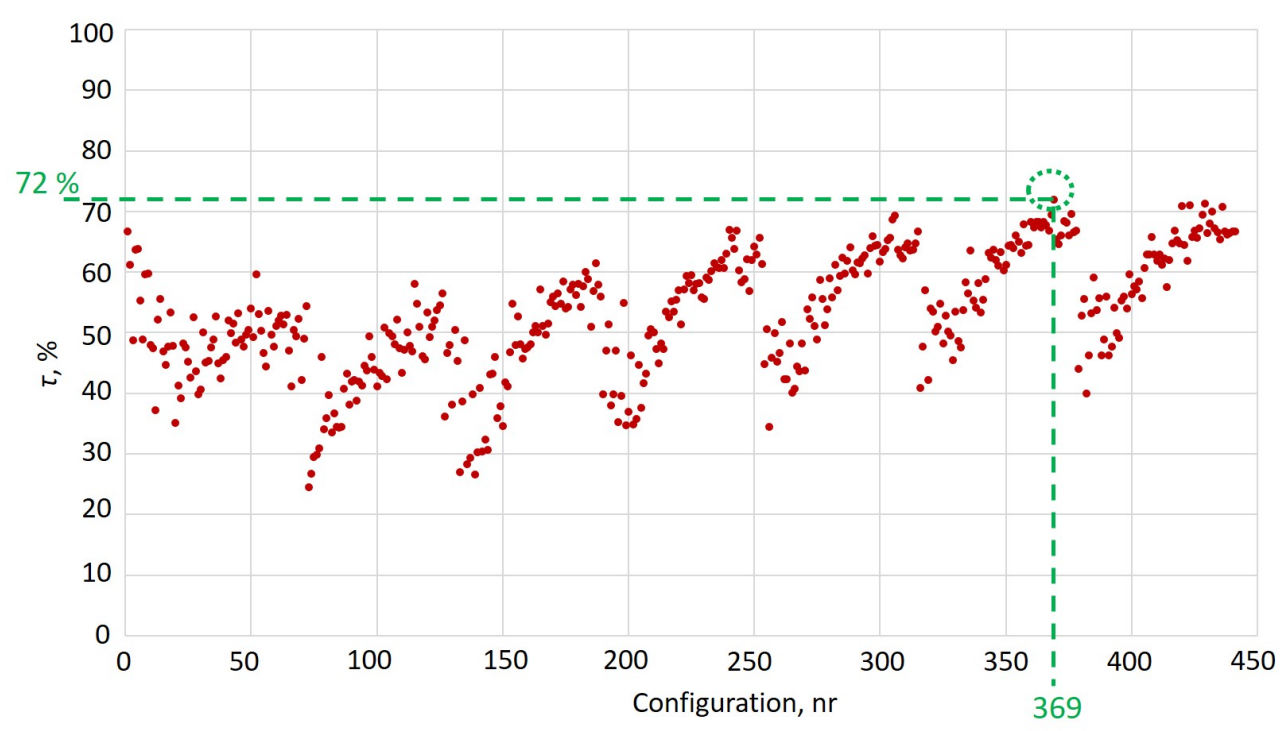

Fig. 7. Correlation between technical benefit score and configuration number using five criteria. Best scenario is indicated in dotted cycle: $\tau_{M A X}=72 \%$ for configuration $\mathrm{nr} .369$, i.e. $\alpha 1=75^{\circ}, \alpha 2=75^{\circ}, \mathrm{h} 1=3.8 \mathrm{~m}, \mathrm{~h} 2=3.8 \mathrm{~m}$.

\section{Conclusions}

In the present study a cost-benefit analysis is performed based on specific evaluation criteria to enable a reliable setting of the optimum configuration of mixing systems in anaerobic digesters of industrial biogas plants. Fluid velocity, its distribution inside the digester and power consumption to rotate the mixers are calculated via a CFD model. An intensive set of CFD simulations was proposed. Low flow velocity values were determined in cases, where the propellers are located with the shaft along the tank radius or slightly tilted from the parallel orientation. Propellers, which are deep-seated inside the tank resulted to be less efficient compared to higher locations.

Regarding the impact of mixing un the energy consumption, the torque moment was also considered for the evaluation. Two different criteria analyses with a different degree of detail are carried-out to select the compromise between high mixing quality and low power consumption. Both analyses show very coherent results.

\section{ACKNOWLEDGEMENT}

This work has been supported by the German Federal Ministry of Education and Research within the program "Forschung an Fachhochschulen" under the grants 22402215 and BioOpt-Mix 03FH031PX4.

The authors would like to thank UTS Products GmbH in Dorfen (Germany) for helpful cooperation. F. Conti is grateful to the University of Padova (Italy) for providing the opportunity to spend research periods in THI Ingolstadt. 


\section{REFERENCES}

[1] Lebranchu A., et al. Impact of shear stress and impeller design on the production of biogas in anaerobic digesters. Bioresource Technology 2017:245:1139-1147. https://doi.org/10.1016/j.biortech.2017.07.113

[2] Djossou A., Conti F. Mesophilic and thermophilic bacteria in anaerobic digestion process. Proceeding of 27th EUBCEEuropean Biomass Conference and Exhibition 2019:942-945. https://doi.org/10.5071/27thEUBCE2019-2CV.6.9

[3] Trentini M., Lorenzon M., Conti F. Biotechnology to investigate the microbial community responsible of biogas production from biomass. Proceeding of 26th EUBCE-European Biomass Conference and Exhibition 2018:816-820. https://doi.org/10.5071/26thEUBCE2018-2CV.5.35

[4] Castellan N., Conti F. Molecular biotechnology to improve biofuel production from biomass. Proceeding of $27^{\text {th }}$ EUBCE-European Biomass Conference and Exhibition 2019:951-957. https://doi.org/10.5071/27thEUBCE20192CV.6.24

[5] Owen W. F. Energy in wastewater treatment. New Jersey: Prentice-Hall Inc., Englewood Cliffs, 1982.

[6] Sindall R. C., Bridgeman J., Carliell-Marquet C. Velocity gradient as a tool to characterize the link between mixing and biogas production in anaerobic waste digesters. Water Science Technology 2013:67(12):2800-2806. https://doi.org/10.2166/wst.2013.206

[7] Naegele H., et al. Electric energy consumption of the full scale research biogas plant "Unterer Lindenhof": results of longterm and full detail measurements. Energies 2012:5:5198-5214. https://doi.org/10.3390/en5125198

[8] Lopez-Jimenez P. A., et al. Application of CFD methods to an anaerobic digester: the case of Ontinyent WWPT, Valencia, Spain. Journal Water Process Engineering 2015:7:131-140. https://doi.org/10.1016/j.jwpe.2015.05.006

[9] Shen F., et al. Improving the mixing performances of rice straw anaerobic digestion for higher biogas production by computational fluid dynamics (CFD) simulation. Applied Biochemistry and Biotechnology 2013:171:626-642. https://doi.org/10.1007/s12010-013-0375-z

[10] Conti F., Saidi A., Goldbrunner M. Numeric simulated-based analysis of the mixing process in anaerobic digesters of biogas plants. Chemical Engineering \& Technology 2020:43:1-9. https://doi.org/10.1002/ceat.201900650

[11] Conti F., Saidi A., Goldbrunner M. CFD modelling of biomass mixing in anaerobic digesters of biogas plants. Environmental and Climate Technologies 2019:23(3):57-69. https://doi.org/10.2478/rtuect-2019-0079

[12] Singh B., Szamosi Z., Simenfalvi Z. State of the art on mixing in an anaerobic digester: a review. Renewable Energy 2019:141:922-936. https://doi.org/10.1016/j.renene.2019.04.072

[13] Kowalczyk A., et al. Different mixing modes for biogas plants using energy crops. Applied Energy 2013:112:465-472. https://doi.org/10.1016/j.apenergy.2013.03.065

[14] Conti F., et al. Thermal behaviour of viscosity of aqueous cellulose solutions to emulate biomass in anaerobic digesters. New Journal of Chemistry 2018:42:1099-1104. https://doi.org/10.1039/c7nj03199h

[15] Conti F., et al. Effect of mixing of waste biomass in anaerobic digesters for production of biogas. IOP Conference Series: Materials Science and Engineering 2018:446:012011. https://doi.org/10.1088/1757-899X/446/1/012011

[16] Gerogiorgis D. I., Ydstie B. E. Multiphysics CFD modelling for design and simulation of a multiphase chemical reactor. Chemical Engineering Research and Design 2005:83(6):603-610. https://doi.org/10.1205/cherd.04364

[17] Wiedemann L., et al. Modeling mixing in anaerobic digesters with computational fluid dynamics validated by experiments. Chemical Engineering \& Technology 2018:41:2101-2110. https://doi.org/10.1002/ceat.201800083

[18] Leonzio G. Study of mixing systems and geometric configurations for anaerobic digesters using CFD analysis. Renewable Energy 2018:123:578-589. https://doi.org/10.1016/j.renene.2018.02.07

[19] Wu B. CFD investigation of turbulence models for mechanical agitation of non-Newtonian fluids in anaerobic digesters. Water Resources 2011:45:2082-2094. https://doi.org/10.1016/j.watres.2010.12.020

[20] Alexopoulos A. H., Maggioris D., Kiparissides C. CFD analysis of turbulence non-homogeneity in mixing vessels: a two-compartment model. Chemical Engineering Science 2002:57(10):1735-1752. https://doi.org/10.1016/S00092509(02)00053-2

[21] Bridgeman J. Computational fluid dynamics modelling of sewage sludge mixing in an anaerobic digester. Advances Engineering Software 2012:44(1):54-62. https://doi.org/10.1016/j.advengsoft.2011.05.037

[22] Dapelo D., Bridgeman J. Assessment of mixing quality in full-scale, biogas-mixed anaerobic digestion using CFD. Bioresource Technology 2018:265:480-489. https://doi.org/10.1016/j.biortech.2018.06.036

[23] Celik I. B., et al. Procedure for estimation and reporting of uncertainty due to discretization in CFD applications. Journal of Fluids Engineering 2008:130(7):0780011-0780014. https://doi.org/10.1115/1.2960953

[24] Conti F., et al. Mixing of a Model Substrate in a Scale-down Laboratory Digester and Processing with a Computational Fluid Dynamics Model. Proceeding of 26 th EUBCE-European Biomass Conference and Exhibition 2018:811-815. https://doi.org/0.5071/26thEUBCE2018-2CV.5.34

[25] Conti F., et al. Monitoring the mixing of an artificial model substrate in a scale-down laboratory digester. Renewable Energy 2019:132:351-362. https://doi.org/10.1016/j.renene.2018.08.013

[26] Anaergia Technologies [Online]. [Accessed 01.09.2020]. Available: www.uts-products.com

[27] Bansal R. K. A textbook of fluid mechanics and hydraulic machines. New Delhi: Laxmi Publ. Ltd, 2005. 
[28] Wiedemann L., et al. Mixing in biogas digesters and development of an artificial substrate for laboratory-scale mixing optimization. Chemical Engineering \& Technology 2017:40(2):238-247. https://doi.org/10.1002/ceat.201600194

[29] Wiedemann L., et al. Investigation and optimization of the mixing in a biogas digester with a laboratory experiment and an artificial model substrate. Proceeding of 25 th EUBCE-European Biomass Conference and Exhibition 2017:889892. https://doi.org/10.5071/25thEUBCE2017-2CV.4.14

[30] Ding J., et al. CFD optimization of continuous stirred-tank (CSTR) reactor for biohydrogen production. Bioresource Technology 2010:101(18):7005-7013. https://doi.org/10.1016/j.biortech.2010.03.146

[31] Keshtkar A., et al. Mathematical modelling of non-ideal mixing continuous flow reactors for anaerobic digestion of cattle manure. Bioresource Technology 2003:87(1):113-124. https://doi.org/10.1016/S0960-8524(02)00104-9

[32] Vesvikar M. S., Al-Dahhan M. Flow pattern visualization in a mimic anaerobic digester using CFD. Biotechnology Bioengineering 2005:89(6):719-732. https://doi.org/10.1002/bit.20388

[33] Saur T., et al. Impact of wall shear stress on initial bacterial adhesion in rotating annular reactor. PLoS ONE 2017:12:0172113. https://doi.org/10.1371/journal.pone.0172113

[34] Garcia-Ochoa F., et al. The effect of hydrodynamic stress on the growth of Xanthomonas campestris cultures in a stirred and sparged tank bioreactor. Bioprocess and Biosystems Engineering 2013:36:911-925. https://doi.org/10.1007/s00449-012-0825-y 